\title{
Stressful Life Events in Young Adults With Type 1 Diabetes in the U.S. T1D Exchange Clinic Registry
}

\author{
Kevin L. Joiner, PhD, RN, ANP-BC ${ }^{1}$ (D) , Margaret L. Holland, PhD, MPH, MS², \& Margaret Grey, DrPH, RN, \\ FAAN $^{3}$ \\ 1 Rho, Research Fellow, University of Michigan School of Nursing, Ann Arbor, MI, USA \\ 2 Associate Research Scientist in Nursing, Yale University School of Nursing, Orange, CT, USA \\ 3 Delta Mu, Annie Goodrich Professor of Nursing, Yale University School of Nursing, Orange, CT, USA
}

\begin{abstract}
Key words
type 1 diabetes mellitus, young adults, stressful

life events, self-management

\section{Correspondence}

Dr. Kevin L. Joiner, Department of Health Behavior and Biological Sciences, School of Nursing, University of Michigan, 400 North Ingalls Street, Ann Arbor, MI 48104.

E-mail:kljoiner@umich.edu
\end{abstract}

Accepted June 27, 2018

doi:10.1111/jnu.12428

\begin{abstract}
Purpose: The purpose was to test associations among stressful life events, frequency of missed insulin doses, and glycemic control in young adults with type 1 diabetes (T1D).
\end{abstract}

Design: The study was a cross-sectional descriptive secondary analysis. Methods: Data from 2,921 participants (ages 18-26 years) in the U.S. T1D Exchange Clinic Registry were analyzed. Report of a stressful life event was defined as one or more positive responses on a 17-item stressful life events index and defined as a dichotomous variable (yes or no). Frequency of missed insulin doses was measured using a single self-report item and collapsed into two levels (fewer than three times a week, three or more times a week). The glycosylated hemoglobin (Alc) level recorded at the time of enrollment was used to assess glycemic control.

Findings: Nearly half $(48.6 \%)$ of the participants reported having a stressful life event during the previous year. The most frequently reported stressful life events were problems at work or school (16.1\%), serious arguments with family members or a close friend $(15.2 \%)$, and financial problems in the family $(13.8 \%)$. Compared to the participants not reporting stressful life events, those who reported stressful life events were more likely to be older, female, with a higher educational attainment level, and not working or unemployed. Those who reported a stressful life event were more likely than those who did not to say they typically missed insulin doses at least three times a week and less likely to say they typically missed insulin doses fewer than three times a week $(p<.001$ adjusted for age, sex, race or ethnicity, educational attainment level, duration of TlD diagnosis, and insulin delivery method). Mean Alc level was higher for the group who reported having a stressful life event in the past 12 months compared to the group who did not $(8.7 \pm 1.8 \%$ vs. $8.2 \pm 1.6 \%$; adjusted $p<.001)$. The results of a mediation analysis suggest that the measure of frequency of missed insulin doses may be a mediator of the relationship between recent stressful life events and glycemic control (Sobel test: $a b=.841,95 \%$ confidence interval $=0.064-1.618$ ).

Conclusions: These findings suggest that, for young adults with T1D, the experience of stressful life events may increase their risk for poorer glycemic control, possibly by disrupting adherence with insulin doses.

Clinical Relevance: Further exploration of these relationships may allow for the potential for identifying those at risk and assisting them with more positive approaches to managing stressful events. 
Young adulthood, defined as ages 18 to 26 years, is a life stage that is of particular importance for people living with type 1 diabetes (TID; Institute of Medicine [IOM] and National Research Council [NRC], 2015; Peters, Laffel, \& American Diabetes Association [ADA] Transitions Working Group, 2011). In the United States, about $75 \%$ of young adults with T1D have glycosylated hemoglobin (Alc) levels that are higher than the ADA's recommended target of $7 \%$ (Miller et al., 2015). Less than ideal glycemic control increases the risk for longterm microvascular and macrovascular complications (Diabetes Control and Complications Trial [DCCT] Research Group, 1993). Having less than ideal glycemic control during this developmental period could disrupt educational pursuits and career efforts that may have profound and long-lasting economic, social, and health implications for these young adults (IOM and NRC, 2015). Patterns of health behaviors (e.g., diet, physical activity, substance use) formed during young adulthood tend to persist into adulthood (Harris, 2010), making it even more important to address these concerns.

Young adulthood is often marked by a number of life events, including graduating from high school, leaving home for the first time, entering college, pursuing a career, forming a committed relationship, and having children (Arnett, 2000). Life events that are unexpected (e.g., acute or chronic illness, death of a friend or family member, job loss) may also occur during this period. Experiencing life events of any kind may result in stress responses that could be intense and prolonged. Under certain circumstances, intense and prolonged stress responses to such events might be adaptive, but the emotional and somatic symptoms of chronic stress responses could be distressing (YoungHyman et al., 2016). A stress response to a life event may also precipitate or exacerbate debilitating psychological conditions, including adjustment disorders, depressed mood, and anxiety (Young-Hyman et al., 2016). These risks may also be heightened by psychosocial factors, such as personality traits, coping style, and health behaviors (Young-Hyman et al., 2016).

During young adulthood, people with T1D assume full responsibility for their diabetes self-management (Peters et al., 2011). For young adults who are struggling with diabetes self-management, the response to stressful life events could result in disruption of the insulin doses that are necessary multiple times per day (basal and prandial insulin injections or appropriate prandial insulin pump boluses; ADA, 2017) and that require a high degree of adherence (Wasserman, Hilliard, Schwartz, \& Anderson, 2015). If insulin doses are missed frequently, it is much more difficult to achieve and maintain the target level of glycemic control (Burdick et al., 2004; Hood, Peterson, Rohan, \& Drotar, 2009). The associations among stressful life events, selfmanagement, and glycemic control have been evaluated in observational studies of adolescents with T1D (Helgeson, Escobar, Siminerio, \& Becker, 2010) and adolescents with type 2 diabetes (Walders-Abramson et al., 2014). While there is evidence of associations between stressful life events and poorer self-management and glycemic control in adolescents, there is limited research on stressful life events in young adults with T1D (Lloyd et al., 1999; Pyatak, Sequeira, Peters, Montoya, \& Weigensberg, 2013; Stenström, Wikby, Hörnqvist, \& Andersson, 1995). Indeed, this population has not been well studied in general (Monaghan, Helgeson, \& Wiebe, 2015). Thus, examining associations among stressful life events, frequency of missed insulin doses, and glycemic control in young adults with TID could inform efforts to find effective interventions to improve their outcomes.

Therefore, the aims of this study were to describe the frequency of stressful life events during the previous year, to describe associations of sociodemographic and clinical characteristics with those self-reported stressful life events, and to explore the relationships of those self-reported stressful life events with selfreported frequency of missed insulin doses and glycemic control.

\section{Research Design and Methods}

This study was an analysis of data from the initial wave of enrollment in the U.S. TID Exchange Clinic Registry (TID Exchange). The TID Exchange is a largescale clinical center-based patient registry that fosters ongoing collaboration among a consortium of diabetes centers as part of an initiative to contribute to clinical, translational, and epidemiological research. The data in the analyzed dataset were collected in the initial wave of enrollment of patients with TlD recruited from the centers into the TID Exchange between September 2010 and August 2012 (Beck et al., 2012).

The T1D Exchange, at the time of the initial wave of enrollment, consisted of 67 clinical sites distributed across the United States, 12 treating primarily adult patients, 36 treating primarily pediatric patients, and 19 treating both adult and pediatric patients. Enrollment of patients into the T1D Exchange was contingent on a presumed clinical diagnosis of autoimmune TID (presence of islet cell autoantibodies and/or started insulin at diagnosis and used insulin continually since diagnosis). The enrollment rate during the initial wave was 97\% (Beck et al., 2012). The study was approved by each center's institutional review board. Informed 
consent from all participants was obtained prior to enrollment in the registry. Upon enrollment, participants received a $\$ 20$ gift card, or a \$20 donation was made to a TID charity of their choice. The Institutional Review Board of Yale University determined that this secondary analysis was exempt.

Included in these analyses were participants in the initial wave of enrollment who met the following inclusion and exclusion criteria: age $\geq 18$ years and $\leq 26$ years, duration of TlD of more than 1 year, and no self-reported current pregnancy. Among the 25,761 participants in the initial wave, 21,790 participants were not included in the study because they did not meet these criteria. Of those, 21,663 participants were not within the target age range. An additional 75 individuals were excluded because their duration of T1D diagnosis was less than 1 year, and 52 were not included because they reported a current pregnancy.

\section{Measures}

\section{Self-reported stressful life events during the previous year}

Recent stressful life events were assessed using two self-report items in the T1D Exchange enrollment questionnaire that were based on the conceptualization of Holmes and Rahe (1967). In the first item, participants were asked, "In the last year, have you experienced a major change in your life situation that caused you to feel 'stressed' or have a physical, mental, or emotional response for an extended period of time?" The response choices were "yes," "no," “don't know," and "do not wish to answer." If a participant selected the response option "yes," he or she was instructed to complete the second item that read, "If yes, which of the following events have you experienced in the past year? Choose all that apply." Participants were asked to indicate which stressful life events they experienced during the previous year from a list of 16 separate events or conditions taken from the Holmes and Rahe work. The participants were also offered a response option of "other." These items have content validity based on the previous work of Holmes and Rahe. For these analyses, participants who reported one or more stressful life events during the past year were categorized as "yes," and participants who did not report any stressful life events during the past year were categorized as "no."

\section{Self-reported frequency of missed insulin doses}

Frequency of missed insulin doses was measured using a single self-report item developed for use in the TID Exchange. Participants were asked, "In a typical week, how often do you miss an insulin dose?" The response options were: "never," "less than once a week," "1 to 2 times a week," "3 to 4 times a week," "5 or more times a week," and "at least once a day." For the analyses, reports of frequency of missed insulin doses were collapsed into two levels (fewer than three times a week; three or more times a week). This cut point, which corresponds to taking between $80 \%$ and $90 \%$ of weekly doses (based on an insulin therapy regimen of three to four doses per day), was chosen to align with the common cutoff of $80 \%$ or more in the research literature on adherence (Asche, LaFleur, \& Conner, 2011; Nguyen, La Caze, \& Cottrell, 2014).

\section{Glycemic control}

The Alc level recorded at the time of enrollment was used to assess glycemic control. Alc levels in the TID Exchange were abstracted from the participants' medical records by registry staff. Measurements of Alc levels in the full T1D Exchange dataset were ascertained by several methods: DCA ${ }^{\circledR}$ point-of-care instruments $(74 \%)$, laboratory assay methods (19\%), other point-of-care instruments (4\%), and unknown assay methods (2\%; Beck et al., 2012). National Alc standardization allows for comparisons of Alc results from different certified laboratories and methods (National Glycohemoglobin Standardization Program, 2017).

\section{Sociodemographic and clinical characteristics}

Sociodemographic and clinical data were collected from the medical record and included age, gender, race or ethnicity, age at TID diagnosis, and insulin delivery method. Questionnaires were used to ascertain educational attainment and employment status. Although self-reported information about household income and insurance data were available in the TID Exchange, these data were not included because of concern about the validity and reliability of the data. A large proportion of the study sample was missing household income $(39.0 \%)$ and insurance $(31.5 \%)$ data. Second, participants age 18 years or older in the TID Exchange were instructed by clinic staff during the enrollment process to complete the survey themselves, and they may or may not have received the assistance of their parents or guardian caregivers in completing the survey. Collecting household income and insurance data directly from young adults can be difficult as many are still economically dependent on their parents and may be unable to respond accurately. Finally, it is common for people to be reluctant to share household income on surveys if there is no perceived benefit for doing so. 


\section{Statistical Analysis}

From the original 3,971 participants who met all the study inclusion and exclusion criteria, 2,921 participants remained in the sample for the analyses. We excluded participants with missing data on stressful life events, frequency of missed insulin doses, or Alc levels. A total of 199 participants (5.0\%) were excluded from the analysis because of missing data on stressful life events. An additional 140 participants $(3.5 \%)$ were excluded because of missing data on frequency of missed insulin doses, and 711 participants $(17.9 \%)$ were excluded because of missing data on Alc levels. Compared to the participants included in the analysis, the participants not included in the analysis due to missing data were more likely to be Black non-Hispanic $(6.7 \%$ vs. $3.8 \% ; p=.001)$ and less likely to use an insulin pump (48.5\% vs. $53.5 \% ; p=.018)$. There were no differences in the distribution of the other characteristics, including age, gender, employment status, and duration of diabetes (all $p>.05$ ). Missing data in the remaining variables in the regression models were imputed using multiple imputation with chained equations (StataCorp, 2011), using 20 imputed datasets. The proportion of missing values imputed was educational attainment $(n=95,3.3 \%)$ and employment status $(n=70,2.4 \%)$.

We tested if reports of stressful life events during the previous year were associated with sociodemographic and clinical factors using a multivariable logistic regression model. Associations were tested among reports of those stressful life events, reports of frequency of missed insulin doses, and Alc levels using logistic regression and linear regression models adjusted for age, sex, race or ethnicity, educational attainment level, duration of T1D diagnosis, and insulin delivery mode (insulin injections or insulin pump). To test the measure of frequency of missed insulin doses as a potential mediator of the relationship between recent stressful life events and glycemic control, we used regression analysis and calculated the Sobel test (Sobel, 1982) for each imputed dataset, and then combined them using Rubin's rules (Rubin \& Schenker, 1986).

The distribution of participant age in the analyzed sample was skewed towards lower ages. Thus, the square transform term of participant age was included in the models. Two-tailed $p$ values of $<.05$ were considered statistically significant in all of the analyses. Analyses were conducted using Stata version 12.1 (StataCorp Inc., College Station, TX, USA).

\section{Results}

The sample $(N=2,921)$ was $47.6 \%$ female, $83.1 \%$ White non-Hispanic, $36.5 \%$ high school graduate or lower, and $55.8 \%$ students (Table 1). Mean age at the time of enrollment was $21.1 \pm 2.5$ years. Median age was 20.4 years (interquartile range 19.0-22.7 years). Mean duration of T1D diagnosis was $10.8 \pm 5.3$ years. Slightly more than half $(53.5 \%)$ used insulin pump therapy. The majority $(57.3 \%)$ reported missing insulin doses less than once a week. Almost half $(42.7 \%)$ reported missing an insulin dose at least once a week, and around one fifth (18.1\%) reported missing insulin doses three or more times a week. Overall, $82.3 \%$ of participants were not meeting the Alc goal of less than $7 \%$ recommended by the ADA.

\section{Sociodemographic and Clinical Characteristics and Stressful Life Events}

Nearly half of the participants ( $n=1,420,48.6 \%$ ) reported one or more stressful life event during the previous year. The most frequently reported stressful life events were problems at work or school $(n=$ $470,16.1 \%)$, followed by serious arguments with family members or a close friend $(n=443,15.2 \%)$, financial problems in the family $(n=402,13.8 \%)$, and moved to a new home $(n=351,12.0 \%$; Table 2$)$. Less frequently reported stressful life events included "went to a new school" $(n=313,10.7 \%)$, failed a class or received a poor report card $(n=266,9.1 \%)$, death of a family member $(n=234,8.0 \%)$, and serious illness or injury $(n=196,6.7 \%)$.

In univariate analyses, self-report of one or more recent stressful life events was more likely in participants who were older, female, with a higher educational attainment level, not working or unemployed, with a longer duration of diabetes (all $p<.001$ ), and Hispanic ( $p=.04$; Table 3$)$. Correlations were similar in a multivariable analysis, except for the correlations between reported stressful life events during the previous year and duration of T1D $(p=.15)$, and stressful life events during the previous year and race and ethnicity $(p=.051)$, which were nonsignificant.

\section{Recent Stressful Life Events, Frequency of Missed Insulin Doses, and Glycemic Control}

Reporting one or more recent stressful life event was associated with reporting missing insulin doses more often (Table 4). Those who reported at least one stressful life event were more likely than those who did not to say that they typically missed insulin 
Table 1. Characteristics of the Study Participants $(N=2,921)$

\begin{tabular}{|c|c|c|c|c|}
\hline & \multirow[b]{2}{*}{$\begin{array}{l}\text { All } \\
(N=2,921)\end{array}$} & \multicolumn{3}{|c|}{ One or more stressful life events } \\
\hline & & $\begin{array}{l}\text { Yes } \\
(n=1,420)\end{array}$ & & $\begin{array}{l}\text { No } \\
(n=1,501)\end{array}$ \\
\hline \multicolumn{5}{|l|}{ Age (years) } \\
\hline Mean $\pm S D$ & $21.07 \pm 2.49$ & $21.30 \pm 2.56$ & & $20.85 \pm 2.39$ \\
\hline $\begin{array}{l}\text { Median } \\
\quad \text { (25th-75th percentile) }\end{array}$ & $\begin{array}{l}20.39 \\
(18.99-22.71)\end{array}$ & $\begin{array}{l}20.58 \\
(19.14-23.25)\end{array}$ & & $\begin{array}{l}20.25 \\
(18.88-22.16)\end{array}$ \\
\hline$p$ value $^{a}$ & & & $<.001$ & \\
\hline Sex, female, $n(\%)$ & $1,389(47.55)$ & $793(55.88)$ & & $596(39.71)$ \\
\hline$p$ value & & & $<.001$ & \\
\hline \multicolumn{5}{|l|}{ Race/ethnicity, n (\%) } \\
\hline White non-Hispanic & $2,426(83.05)$ & $1,157(81.48)$ & & $1,269(84.54)$ \\
\hline Black non-Hispanic & $110(3.77)$ & $60(4.23)$ & & $50(3.33)$ \\
\hline Hispanic or Latino & $279(9.55)$ & $155(10.92)$ & & $124(8.26)$ \\
\hline Other race/ethnicity & $106(3.63)$ & 48 (3.38) & & $58(3.86)$ \\
\hline p value $e^{b}$ & & & .042 & \\
\hline \multicolumn{5}{|l|}{ Education level, $n(\%)$} \\
\hline Less than high school graduate & $272(9.31)$ & $118(8.31)$ & & $154(10.26)$ \\
\hline High school diploma/GED & 794 (27.18) & $352(24.79)$ & & $442(29.45)$ \\
\hline Some college/associate's & $1,185(40.57)$ & $626(44.08)$ & & $559(37.24)$ \\
\hline Bachelor's degree & 508 (17.39) & $256(18.03)$ & & $252(16.79)$ \\
\hline Master's/PhD/professional degree & $67(2.29)$ & $37(2.61)$ & & $30(2.00)$ \\
\hline p value ${ }^{b}$ & & & .001 & \\
\hline \multicolumn{5}{|l|}{ Employment status, $n$ (\%) } \\
\hline Student & $1,629(55.77)$ & $734(51.69)$ & & $895(59.63)$ \\
\hline Working full time/part time & 979 (33.52) & $511(35.99)$ & & $468(31.18)$ \\
\hline Not working & $243(8.32)$ & $144(10.14)$ & & $99(6.60)$ \\
\hline$p$ value $e^{b}$ & & & $<.001$ & \\
\hline \multicolumn{5}{|l|}{ Duration of T1D diagnosis (years) } \\
\hline Mean $\pm S D$ & $10.80 \pm 5.31$ & $11.17 \pm 5.26$ & & $10.45 \pm 5.34$ \\
\hline$p$ value & & & $<.001$ & \\
\hline \multicolumn{5}{|l|}{ Insulin delivery method, $n$ (\%) } \\
\hline pump & $1,563(53.51)$ & $764(53.80)$ & & $799(53.23)$ \\
\hline Multiple daily injections & $1,201(41.12)$ & $574(40.42)$ & & $627(41.77)$ \\
\hline Fixed & $157(5.37)$ & $82(5.77)$ & & $75(5.00)$ \\
\hline$p$ value $e^{b}$ & & & .552 & \\
\hline \multicolumn{5}{|l|}{ Missed insulin doses, n/week (\%) } \\
\hline Never & $817(27.97)$ & $314(22.11)$ & & $503(33.51)$ \\
\hline Less than once a week & $858(29.37)$ & $405(28.52)$ & & $453(30.18)$ \\
\hline 1-2 times a week & $718(24.58)$ & $382(26.90)$ & & $336(22.39)$ \\
\hline 3-4 times a week & $364(12.46)$ & $213(15.00)$ & & $151(10.06)$ \\
\hline 5 or more times a week & $106(3.63)$ & $62(4.37)$ & & $44(2.93)$ \\
\hline At least once a day & $58(1.99)$ & $44(3.10)$ & & $14(0.93)$ \\
\hline p value ${ }^{\mathrm{b}}$ & & & $<.001$ & \\
\hline $\mathrm{A} 1 \mathrm{c}<7 \%, n(\%)$ & $517(17.70)$ & $199(14.01)$ & & 318 (21.19) \\
\hline$p$ value & & & $<.001$ & \\
\hline
\end{tabular}

Note. $\mathrm{A} 1 \mathrm{c}=$ glycated hemoglobin; $\mathrm{GED}=$ general educational development; $\mathrm{T} 1 \mathrm{D}=$ type 1 diabetes.

${ }^{a} p$ value from Wilcoxon rank-sum test.

${ }^{b} p$ value from $x^{2}$ test.

${ }^{c} p$ value from $t$-test.

doses three or more times a week and less likely to say they typically missed insulin doses fewer than three times a week $(p<.001$ adjusted for age, sex, race or ethnicity, educational attainment level, duration of
TID diagnosis, and insulin delivery method). Mean Alc level was higher for the group who reported having a stressful life event in the past 12 months compared to the group who did not $(8.7 \pm 1.8 \%$ vs. 
Table 2. Self-Reported Stressful Life Events in the Previous 12 Months $(N=2,921)$

\begin{tabular}{llc}
\hline Stressful life event & Frequency & $\%^{\mathrm{a}}$ \\
\hline Problems at work or school & 470 & 16.09 \\
Serious arguments with family members or a & 443 & 15.17 \\
close friend & 402 & 13.76 \\
Financial problems in the family & 351 & 12.02 \\
Moved to a new home & 313 & 10.72 \\
Went to a new school & 266 & 9.11 \\
Failed a class or received a poor report card & 234 & 8.01 \\
Death of a family member & 196 & 6.71 \\
Serious illness or injury & 155 & 5.31 \\
Job loss (self, spouse, or parents) & 139 & 4.76 \\
Separation or divorce (self or parents) & 136 & 4.66 \\
Hospitalization of a family member & 133 & 4.55 \\
Serious illness or injury in a family member & 107 & 3.66 \\
Parent, close relative, or friend moved away & 107 & 3.66 \\
Death of a close friend & 81 & 2.77 \\
Legal problems in the family & 62 & 2.12 \\
Birth of a child, new step-parent(s), or a relative & & \\
moves in with family & 403 & 13.80 \\
Other &
\end{tabular}

apercent calculated based on number of participants who indicated that the event occurred in the previous year.

$8.2 \pm 1.6 \%$; adjusted $p<.001)$. We also examined whether missed insulin doses mediated reports of stressful life events and glycemic control. The results suggest that frequency of missed insulin doses may be a mediator of the relationship between self-report of one or more recent stressful life events and Alc level from the time of enrollment (Sobel test: $a b=.841,95 \%$ confidence interval $=0.064-1.618)$.

\section{Discussion}

Previous studies have led to the conclusion that, for many young adults with T1D, keeping Alc at the levels that are recommended for improving their chances of preventing or slowing the progression of diabetes complications has been challenging. Although the revolution of diabetes technologies currently underway, including the advent of sensor-augmented automatic insulin pumps, promises to ease more of the burden of self-management in the near future (Sherr et al., 2016), achieving and maintaining optimal glycemic control in T1D requires intensive diabetes management that includes multiple doses of insulin with meals that are appropriately timed and titrated by the amount of carbohydrates ingested and the preprandial blood glucose level. Thus, it is noteworthy we found a higher frequency of missed insulin doses and poorer Alc levels in our sample in those who reported at least one stressful life event. Among the nearly 3,000 young adults with TID who participated in the initial wave of the TID Exchange and were included in our sample, the prevalence of at least one self-reported stressful life event during the previous year was $48.6 \%$. Compared to the Alc level of those who did not report stressful life events $(8.2 \%)$, the Alc level of these young adults $(8.7 \%)$ was $0.5 \%$ higher. Alc levels reflect glycemic control (fasting and postprandial glucose levels) over a 2- to 3-month period (ADA, 2017). Better levels of glycemic control have been shown to have the demonstrated benefits of lesser rates of progression of macrovascular and microvascular complications (DCCT, 1993, 1995; Fullerton et al., 2014). In the landmark DCCT (1993), even apparently small increases in baseline Alc levels $(0.3 \%)$ were associated with appreciable increases in the number of cases of progressive retinopathy over the course of 9 years. A difference in Alc levels of $0.5 \%$, the magnitude of the difference in the group mean Alc levels found in the present study, is generally regarded as a difference that is clinically significant (Cummins et al., 2010). Evidence indicates that the mean Alc level among young adults (18-25 years old) with T1D in the United States is $8.7 \%$ (Miller et al., 2015). In addition, self-reported stressful life events were associated with more frequently missing insulin doses.

While periodic lapses in self-management are expected among individuals with T1D (ADA, 2017), the findings of this study support the need for ongoing assessment and treatment of psychosocial factors such as the distress related to stressful life events that may be associated with poorer self-management behaviors and poorer glycemic outcomes (Young-Hyman et al., 2016). Although it was not possible to assess these relationships longitudinally, the cross-sectional design allowed us to describe the prevalence of stressful life events during the previous year, the frequency of missed insulin doses, and glycemic control in this understudied highrisk population. In addition, we were able to explore the relationships among these variables in a large-scale sample with wide geographic dispersion.

The findings of this study contribute to the current state of research on stressful life events experienced by young adults with TID and the relationships among these general life stressors, self-management, and outcomes (Hilliard et al., 2016). The findings are consistent with previous evidence that stressful life events during young adulthood may have implications for diabetes self-management behaviors and glycemic control (Pyatak et al., 2013; Rasmussen, Ward, Jenkins, King, \& Dunning, 2011). Helgeson et al. (2010) found that adolescents with TID who reported stressful life events were more likely to experience deterioration of glycemic control, 
Table 3. Associations Between Sociodemographic and Clinical Characteristics and Self-Report of One or More Stressful Life Events During the Previous Year $(N=2,921)$

\begin{tabular}{|c|c|c|c|c|}
\hline & $\begin{array}{l}\text { Unadjusted } \\
\text { OR (95\% Cl) }\end{array}$ & $p$ value & $\begin{array}{l}\text { Full-model } \\
\text { OR }(95 \% \mathrm{Cl})\end{array}$ & $p$ value \\
\hline Age & & $<.001$ & & .035 \\
\hline Age (years) & $1.19(1.09-1.31)$ & & $1.10(0.96-1.26)$ & \\
\hline Age squared & $1.01(0.93-1.09)$ & & $1.05(0.96-1.15)$ & \\
\hline Sex & & $<.001$ & & $<.001$ \\
\hline Male & 1.0 & & & \\
\hline Female & $1.93(1.66-2.23)$ & & $1.91(1.64-2.22)$ & \\
\hline Race/ethnicity & & .042 & & .051 \\
\hline White non-Hispanic & 1.0 & & & \\
\hline Black non-Hispanic & $1.32(0.90-1.93)$ & & $1.31(0.88-1.95)$ & \\
\hline Hispanic or Latino & $1.37(1.07-1.76)$ & & $1.39(1.07-1.80)$ & \\
\hline Other race/ethnicity & $0.91(0.61-1.34)$ & & $0.91(0.61-1.36)$ & \\
\hline Duration of T1D (years) & $1.03(1.01-1.04)$ & $<.001$ & $1.01(1.00-1.03)$ & .153 \\
\hline Insulin delivery method & & .552 & & .446 \\
\hline Pump & 1.0 & & & \\
\hline Multiple daily injections & $0.96(0.82-1.11)$ & & $0.93(0.80-1.10)$ & \\
\hline Fixed & $1.14(0.82-1.59)$ & & $1.14(0.81-1.61)$ & \\
\hline Education level & & $<.001$ & & .005 \\
\hline Less than high school graduate & 1.0 & & & \\
\hline High school diploma/GED & $1.05(0.80-1.39)$ & & $1.02(0.76-1.36)$ & \\
\hline Some college/associate's degree & $1.47(1.13-1.92)$ & & $1.35(1.00-1.84)$ & \\
\hline Bachelor's degree & $1.34(1.00-1.79)$ & & $0.94(0.64-1.39)$ & \\
\hline Master's/PhD/professional degree & $1.65(0.97-2.82)$ & & $0.94(0.50-1.74)$ & \\
\hline Employment status & & $<.001$ & & $<.001$ \\
\hline Student & 1.0 & & & \\
\hline Working full time/part time & $1.33(1.14-1.56)$ & & $1.25(1.05-1.50)$ & \\
\hline Not working & $1.77(1.35-2.33)$ & & $1.73(1.29-2.31)$ & \\
\hline
\end{tabular}

Note. $\mathrm{Cl}$ = confidence interval; GED = general educational development; $\mathrm{OR}=$ odds ratio; T1D = type 1 diabetes.

and this association may be mediated by poorer selfmanagement behaviors. Recently it was reported that the experience of four or more stressful life events within the previous 12 months in adolescents with T1D was related to poorer general performance of self-care behaviors (exercise, meal timing at regular intervals, and insulin therapy adherence) and poorer glycemic control (Commissariat et al., 2018). Our data suggest that among the behaviors involved in selfmanagement of T1D, missed insulin doses may be particularly salient to assess in young adult populations. Previous work in adolescents and young adults has also shown that stressful life events during these periods of development are related to symptoms of anxiety, depression, substance abuse, and self-harm (Bodenlos, Noonan, \& Wells, 2013; Gress-Smith, Roubinov, Andreotti, Compas, \& Luecken, 2015; Jackson \& Finney, 2002). Furthermore, young adults struggling with psychosocial conditions or behavioral health disorders often do not seek appropriate help due to a variety of factors, including feelings of fear and shame that they may have a mental illness, perceiving that they do not need help, not realizing that they may need help,
Table 4. Frequency of Missed Insulin Doses and Glycemic Control in Participants With Stressful Life Events Versus Participants Without Stressful Life Events ( $N=2,921)$

\begin{tabular}{|c|c|c|c|}
\hline & \multirow[b]{2}{*}{$\begin{array}{l}\text { All } \\
(N=2,921)\end{array}$} & \multicolumn{2}{|c|}{ One or more stressful life events } \\
\hline & & $\begin{array}{l}\text { Yes } \\
(n=1,420)\end{array}$ & $\begin{array}{l}\text { No } \\
(n=1,501)\end{array}$ \\
\hline \multicolumn{4}{|c|}{ Frequency of missed insulin doses, $n(\%)$} \\
\hline$<3$ times a week & $2,393(81.92)$ & $1,101(77.54)$ & $1,292(86.08)$ \\
\hline $\begin{array}{l}\geq 3 \text { times a week } \\
p \text { value }\end{array}$ & $528(18.08)$ & $\begin{array}{l}319(22.46) \\
<.001\end{array}$ & $209(13.92)$ \\
\hline \multicolumn{4}{|c|}{ Most recent $\mathrm{A} 1 \mathrm{c}(\%)$} \\
\hline $\begin{array}{l}\text { Mean } \pm S D \\
p \text { value }^{b}\end{array}$ & $8.42 \pm 1.74$ & $\begin{array}{l}8.68 \pm 1.82 \\
<.001\end{array}$ & $8.17 \pm 1.63$ \\
\hline
\end{tabular}

a $p$ value from logistic regression model, adjusted for age, sex, race/ ethnicity, education, diabetes duration, and insulin delivery method. ${ }^{\mathrm{b}} p$ value from linear regression model, adjusted for age, sex, race/ ethnicity, education, diabetes duration, and insulin delivery method.

and distrusting healthcare providers and their commitment to keep their concerns confidential (Gulliver, Griffiths, \& Christensen, 2010). 
Thus, while further research with more robust designs is needed on stressful life events in young adults with T1D, adolescence and young adulthood appear to be life stages when stressful life events are linked to challenges in adherence with self-management behaviors and poorer glycemic control. Clearly, much more remains to be learned about the experiences of stressful life events during these critical periods of development among people with T1D. Group-based interventions that support the development of effective stress management such as coping skills training have been employed effectively in youth and adolescents with TlD to support the challenges of managing life stressors (Grey, Boland, Davidson, Yu, \& Tamborlane, 1999). Further research is needed to determine whether these types of interventions are effective in young adults with TID. Clinically, the findings of the present study highlight the need for team-based care in which there is social support from qualified healthcare providers with behavioral expertise readily available for young adults with T1D during stressful experiences.

Several limitations need to be acknowledged. First, the sample of young adults in the TID Exchange may not be representative of the larger population of young adults with T1D in the United States since the TID Exchange is not a population-based registry. Setting the age bracket as inclusion criteria between 18 and 26 years resulted in a final sample that was skewed toward lower ages. A different age bracket might produce different results. This age bracket was selected based in recognition of young adulthood as a functionally coherent period of life development (Arnett, 2000), with a distinct set of complex challenges of integrating T1D into daily life (Peters et al., 2011).

Disparities and inequities in healthcare access and health outcomes among subgroups of the population of young adults with TID are major concerns. The final sample was not representative of the racial and ethnic diversity of the TID population. The largest portion of the analyzed sample were non-Hispanic Whites (83\%), followed by Hispanics (10\%), and non-Hispanic Blacks (4\%). Compared to non-Hispanic Whites, non-Hispanic Blacks were more likely to be dropped from the initial sample due to missing information on key variables. It was not possible to include data on household income or health insurance in our models because for a large portion of the sample the data were missing. Thus, we were unable to account for the expense of different pharmacotherapies and technologies.

Data were collected at a point in time, 6 to 8 years ago, which raises concerns that the findings of the study may not reflect the current state of diabetes care. The dissemination of the pharmacotherapy and technology in widespread use today, including rapidacting and long-acting insulin analogs and continuous subcutaneous insulin infusion pump therapy technologies, has been going on for the past 15 years. Not reflected in these data are the most recent advancements in the sensor-augmented automatic insulin pumps that are just beginning to be translated into routine TID care (Sherr et al., 2016).

Stressful life events were assessed using a yes or no checklist developed for use in the TID Exchange without strong evidence of validity and reliability. While this approach allowed for assessment of self-reported stressful life events, it lacked a component to explore the meaning of those events from the participants' perspectives that is present in other methods of measurement (Alloy et al., 2000). It also included only a limited number of potentially stressful events. Frequency of missed insulin doses was also assessed using selfreport. There is a tendency for participants to inflate their adherence rates, due to social desirability and memory bias (Stirratt et al., 2015). However, in this study, $18 \%$ admitted to at least three missed insulin doses per week, and $43 \%$ admitted to at least one missed insulin dose per week. These rates of missed insulin doses were in line with previous findings in children and adolescents with T1D (Driscoll \& YoungHyman, 2014). In this study, data were presented on the insulin doses that were missed in a typical week. Information regarding the number of insulin doses that were taken in a typical day or week was not available in the dataset. As new technologies that facilitate diabetes self-management (e.g., insulin pumps that record times, dates, and amounts of insulin boluses) are adopted, it may be appropriate in future studies in young adults to use technologies such as these to capture more objective adherence data (Driscoll \& Young-Hyman, 2014). We were also unable to assess economic and insurance status due to limited availability of reliable data in the study sample. Our cross-sectional data did not allow for the mediation analysis to include measures in the appropriate temporal order (i.e., we do not know if stressful life events preceded missed insulin doses resulting in higher Alc). However, the life events were within the 12 months preceding the survey, the missed insulin doses were regarding a "typical" week, which is likely to represent the current and recent practices, and Alc levels were at the time of enrollment, which were representative of glycemic control over the past 3 months. Based on the timing of each of these measures, it is likely that they occurred in the order consistent with mediation, although we cannot confirm this and there may be 
individuals with very recent stressful life events who would not fit this pattern. Lastly, past research in adults with TID has found that stressful life events were associated with emotional distress and depressive symptoms (Bryden, Dunger, Mayou, Peveler, \& Neil, 2003). While it is conceivable that stressful life events could have triggered depression and anxiety in some individuals that may have affected TID self-management behaviors and glycemic control, these constructs could not be examined in the study due to the absence of measures assessing these factors in the dataset; this is an area that needs future research.

\section{Conclusions}

If the findings of this study are supported by further research, the experience of stressful life events may play a larger role in self-management behaviors and glycemic control than previously recognized among young adults with TlD. A high proportion of these young adults have poorer glycemic control that is associated with a higher risk for developing complications that can negatively impact their lives. The findings of this study reinforce the need for making appropriate levels of psychosocial care more accessible for young adults with TID. Parents, peers, diabetes care providers, and others need to be aware of how common these events can be during young adulthood and their potential impact on self-management behaviors and TID outcomes. Systematic screening for stressful life events and collaborating with qualified mental health professionals on the diabetes treatment team to provide behavioral healthcare services that are more accessible may help to reach young adults with T1D who may be suffering from distress related to stressful life events. Interventions need to be developed that can mitigate the impact of these stressful experiences, and these interventions need to be tested. For example, coping skills training has been found effective in reducing stress in adolescents with TID (Grey et al., 1999) and may provide an approach to improving management of stress in young adults. Ultimately, such approaches may help to improve the lives of people with T1D.

\section{Acknowledgments}

This research was supported in part by research awards from the National Institutes of Health (Award Number T32DK097718) and the Delta Mu Chapter of Sigma Theta Tau International. We thank the TlD Exchange for the use of this publicly available dataset.
The source of the data is the TID Exchange, but the analyses, content, and conclusions presented herein are solely the responsibility of the authors and have not been reviewed or approved by the T1D Exchange.

\section{Clinical Resources}

- American Association of Diabetes Educators. On-line resources for healthy coping. https:// www.diabeteseducator.org/living-with-diabetes/ aade7-self-care-behaviors/healthy-coping

- American Diabetes Association. On-line resources for healthy coping. http://www.diabetes. org/living-with-diabetes/complications/mentalhealth/stress.html

- College Diabetes Network. On-line resources. https://www.collegediabetesnetwork.org/

\section{References}

Alloy, L. B., Abramson, L. Y., Hogan, M. E., Whitehouse, W. G., Rose, D. T., Robinson, M. S., \& Lapkin, J. B. (2000). The Temple-Wisconsin Cognitive Vulnerability to Depression Project: Lifetime history of axis I psychopathology in individuals at high and low cognitive risk for depression. Journal of Abnormal Psychology, 109(3), 403-418. https://doi.

org/10.1037/0021-843X.109.3.403

American Diabetes Association. (2017). Standards of medical care in diabetes-2017. Diabetes Care, 40(Suppl. 1), S1-S135.

Arnett, J. J. (2000). Emerging adulthood: A theory of development from the late teens through the twenties. American Psychologist, 55(5), 469-480. https://doi.org/10.1037/0003-066x.55.5.469

Asche, C., LaFleur, J., \& Conner, C. (2011). A review of diabetes treatment adherence and the association with clinical and economic outcomes. Clinical Therapeutics, 33(1), 74-109. https://doi. org/10.1016/j.clinthera.2011.01.019

Beck, R. W., Tamborlane, W. V., Bergenstal, R. M., Miller, K. M., DuBose, S. N., \& Hall, C. A. (2012). The T1D Exchange Clinic Registry. Journal of Clinical Endocrinology Metabolism, 97(12), 43834389. https://doi.org/10.1210/jc.2012-1561

Bodenlos, J. S., Noonan, M., \& Wells, S. Y. (2013). Mindfulness and alcohol problems in college students: The mediating effects of stress. Journal of American College Health, 61(6), 371-378. https://doi. org/10.1080/07448481.2013.805714 
Bryden, K. S., Dunger, D. B., Mayou, R. A., Peveler, R. C., \& Neil, H. A. W. (2003). Poor prognosis of young adults with type 1 diabetes: A longitudinal study. Diabetes Care, 26(4), 1052-1057. https://doi. org/10.2337/diacare.26.4.1052

Burdick, J., Chase, H. P., Slover, R. H., Knievel, K., Scrimgeour, L., Maniatis, A. K., \& Klingensmith, G. J. (2004). Missed insulin meal boluses and elevated hemoglobin Alc levels in children receiving insulin pump therapy. Pediatrics, $113(3$ Part 1), e221-e224. https://doi.org/10.1542/peds.113.3.e221

Commissariat, P. V., Volkening, L. K., Guo, Z., ElBach, J. L., Butler, D. A., \& Laffel, L. M. (2018). Associations between major life events and adherence, glycemic control, and psychosocial characteristics in teens with type 1 diabetes. Pediatric Diabetes, 19(1), 85-91. https://doi. org/10.1111/pedi.12523

Cummins, E., Royle, P., Snaith, A., Greene, A., Robertson, L., McIntyre, L., \& Waugh, N. (2010). Clinical effectiveness and cost-effectiveness of continuous subcutaneous insulin infusion for diabetes: Systematic review and economic evaluation. Health Technology Assessment, 14(11), iii-iv, xi-xvi, 1-181. https://doi.org/10.3310/hta14110

Diabetes Control and Complications Trial Research Group. (1993). The effect of intensive treatment of diabetes on the development and progression of long-term complications in insulin-dependent diabetes mellitus. New England Journal of Medicine, 329(14), 977-986. https://doi.org/10.1056/ nejm199309303291401

Diabetes Control and Complications Trial Research Group. (1995). The relationship of glycemic exposure (HbAlc) to the risk of development and progression of retinopathy in the diabetes control and complications trial. Diabetes, 44(8), 968-983. https://doi.org/10.2337/diab.44.8.968

Driscoll, K. A., \& Young-Hyman, D. (2014). Use of technology when assessing adherence to diabetes self-management behaviors. Current Diabetes Reports, 14(9), 521. https://doi.org/10.1007/s11892-014-0521-1

Fullerton, B., Jeitler, K., Seitz, M., Horvath, K., Berghold, A., \& Siebenhofer, A. (2014). Intensive glucose control versus conventional glucose control for type 1 diabetes mellitus. Cochrane Database of Systematic Reviews, 2017(12), CD009122. https://doi. org/10.1002/14651858.cd009122.pub2

Gress-Smith, J. L., Roubinov, D. S., Andreotti, C., Compas, B. E., \& Luecken, L. J. (2015). Prevalence, severity and risk factors for depressive symptoms and insomnia in college undergraduates. Stress and Health, 31(1), 63-70. https://doi. org/10.1002/smi.2509
Grey, M., Boland, E. A., Davidson, M., Yu, C., \& Tamborlane, W. V. (1999). Coping skills training for youths with diabetes on intensive therapy. Applied Nursing Research, 12(1), 3-12. https://doi. org/10.1016/S0897-1897(99)80123-2

Gulliver, A., Griffiths, K. M., \& Christensen, H. (2010). Perceived barriers and facilitators to mental health help-seeking in young people: A systematic review. BMC Psychiatry, 10, 113. https://doi. org/10.1186/1471-244x-10-113

Harris, K. M. (2010). An integrative approach to health. Demography, 47(1), 1-22. https://doi. org/10.1353/dem.0.0091

Helgeson, V. S., Escobar, O., Siminerio, L., \& Becker, D. (2010). Relation of stressful life events to metabolic control among adolescents with diabetes: 5-year longitudinal study. Health Psychology, 29(2), 153-159. https://doi.org/10.1037/a0018163

Hilliard, M. E., Yi-Frazier, J. P., Hessler, D., Butler, A. M., Anderson, B. J., \& Jaser, S. (2016). Stress and Alc among people with diabetes across the lifespan. Current Diabetes Reports, 16(8), 67. https:// doi.org/10.1007/s1 1892-016-0761-3

Holmes, T. H., \& Rahe, R. H. (1967). The Social Readjustment Rating Scale. Journal of Psychosomatic Research, 11(2), 213-218. https://doi. org/10.1016/0022-3999(67)90010-4

Hood, K. K., Peterson, C. M., Rohan, J. M., \& Drotar, D. (2009). Association between adherence and glycemic control in pediatric type 1 diabetes: A meta-analysis. Pediatrics, 124(6), el171-e1179. https://doi.org/10.1542/peds.2009-0207

Institute of Medicine and National Research Council. (2015). Investing in the health and well-being of young adults. Washington, DC: The National Academies Press.

Jackson, P., \& Finney, M. (2002). Negative life events and psychological distress among young adults. Social Psychology Quarterly, 65(2), 186-201. https://doi.org/10.2307/3090100

Lloyd, C. E., Dyer, P. H., Lancashire, R. J., Harris, T., Daniels, J. E., \& Barnett, A. H. (1999). Association between stress and glycemic control in adults with type 1 (insulin-dependent) diabetes. Diabetes Care, 22(8), 1278-1283. https://doi. org/10.2337/diacare.22.8.1278

Miller, K. M., Foster, N. C., Beck, R. W., Bergenstal, R. M., DuBose, S. N., DiMeglio, L. A., \& Tamborlane, W. V. (2015). Current state of type 1 diabetes treatment in the U.S.: Updated data from the T1D Exchange Clinic Registry. Diabetes Care, 38(6), 971-978. https://doi.org/10.2337/dc15-0078

Monaghan, M., Helgeson, V., \& Wiebe, D. (2015). Type 1 diabetes in young adulthood. Current 
Diabetes Reviews, 11(4), 239-250. https://doi.org/10.2 174/1573399811666150421114957

National Glycohemoglobin Standardization Program. (2017). NGSP: Background. Retrieved from http:// www.ngsp.org/index.asp

Nguyen, T. M., La Caze, A. L., \& Cottrell, N. (2014). What are validated self-report adherence scales really measuring? A systematic review. British Journal of Clinical Pharmacology, 77(3), 427-445. https://doi.org/10.1111/bcp.12194

Peters, A., Laffel, L., \& American Diabetes Association Transitions Working Group. (2011). Diabetes care for emerging adults: Recommendations for transition from pediatric to adult diabetes care systems. Diabetes Care, 34(11), 2477-2485. https:// doi.org/10.2337/dc1 1-1723

Pyatak, E. A., Sequeira, P., Peters, A. L., Montoya, L., \& Weigensberg, M. J. (2013). Disclosure of psychosocial stressors affecting diabetes care among uninsured young adults with type 1 diabetes. Diabetic Medicine, 30(9), 1140-1144. https://doi. org/10.1111/dme.12248

Rasmussen, B., Ward, G., Jenkins, A., King, S. J., \& Dunning, T. (2011). Young adults' management of type 1 diabetes during life transitions. Journal of Clinical Nursing, 20(13-14), 1981-1992. https://doi. org/10.1111/j.1365-2702.2010.03657.x

Rubin, D. B., \& Schenker, N. (1986). Multiple imputation for interval estimation from simple random samples with ignorable nonresponse. Journal of the American Statistical Association, 81(394), 366-374. https://doi.org/10.1080/01621459.1986.10478280

Sherr, J. L., Hermann, J. M., Campbell, F., Foster, N. C., Hofer, S. E., Allgrove, J., \& Warner, J. T. (2016). Use of insulin pump therapy in children and adolescents with type 1 diabetes and its impact on metabolic control: Comparison of results from three large, transatlantic paediatric registries. Diabetologia, 59(1), 87-91. https://doi.org/10.1007/ s00125-015-3790-6
Sobel, M. E. (1982). Asymptotic confidence intervals for indirect effects in structural equation models. Sociological Methodology, 13, 290-312. https://doi. org/10.2307/270723

StataCorp. (2011). STATA multiple imputation reference manual: Release 12. College Station, TX: Stata Press.

Stenström, U., Wikby, A., Hörnqvist, J. O., \& Andersson, P. O. (1995). Recent life events, gender differences, and the control of insulin-dependent diabetes mellitus. A 2-year follow-up study. General Hospital Psychiatry, 17(6), 433-439. https://doi. org/10.1016/0163-8343(95)00059-3

Stirratt, M. J., Dunbar-Jacob, J., Crane, H. M., Simoni, J. M., Czajkowski, S., Hilliard, M. E., \& Nilsen, W. J. (2015). Self-report measures of medication adherence behavior: Recommendations on optimal use. Translational Behavioral Medicine, 5(4), 470-482. https://doi. org/10.1007/s13142-015-0315-2

Walders-Abramson, N., Venditti, E. M., Ievers-Landis, C. E., Anderson, B., El Ghormli, L., \& Geffner, M.,... Yasuda, P. (2014). Relationships among stressful life events and physiological markers, treatment adherence, and psychosocial functioning among youth with type 2 diabetes. Journal of Pediatrics, 165(3), 504-508, e501. https://doi. org/10.1016/j.jpeds.2014.05.020

Wasserman, R. M., Hilliard, M. E., Schwartz, D. D., \& Anderson, B. J. (2015). Practical strategies to enhance executive functioning and strengthen diabetes management across the lifespan. Current Diabetes Reports, 15(8), 52. https://doi.org/10.1007/ s1 1892-015-0622-5

Young-Hyman, D., De Groot, M., Hill-Briggs, F., Gonzalez, J. S., Hood, K., \& Peyrot, M. (2016). Psychosocial care for people with diabetes: A position statement of the American Diabetes Association. Diabetes Care, 39(12), 2126-2140. https://doi.org/10.2337/dc16-2053 